\title{
A study for exploring the relationship of Internet Addiction with Self-Esteem and Locus of Control
}

\author{
Meghna Basu Thakur ${ }^{1}$, Bhavna Suleria ${ }^{2}$ \\ ${ }^{1}$ Head \& Assistant Professor, ${ }^{2}$ Assistant professor, Department of Psychology,R D National College \\ Mumbai \\ Corresponding author: Ms. Meghna Basu Thakur \\ Email-meghnabasuthakur@yahoo.com
}

\begin{abstract}
Background: The present study based on Technology and Mental Health is an attempt to explore the relationship of Internet Addiction with Self-Esteem and Locus of Control. Previous research has showed a link between Internet Addiction and Self-Esteem that is if person has low Self-Esteem there are more likely to be internet addict. In this study there is an attempt to test whether there is any relationship between Internet Addiction and Locus of Control and how Self-Esteem and Locus of Control are related.

Methods: For this study 30 students of RD National College participated and answered scales of Internet Addiction Test (IAT) given by Dr. Kimberly Young, Rotter's Locus of Control and Self Esteem scale by Rosenberg. Thus, the following hypothesis has been formulated for the present study which is to study the relationship between Internet Addiction with Self-Esteem and Locus of Control. The appropriate inferential statistic to be used is One Way ANOVA as there are 2 IVs with 1 level each.

Results: The results obtained are of the 30 students of R.D. National College who participated in the study. One way ANOVA for Internet Addiction and Self-Esteem was F-value of 1.745 (not significant). The obtained data had high self-esteem thus showing a negative relationship between Internet Addiction and Self-Esteem.

Conclusion: The present study was validated by the previous researches which have stated that high scores on Internet addiction are negatively related to high self-esteem.
\end{abstract}

Keywords: Internet Addiction, Self-Esteem, Locus of Control.

(Paper received $-5^{\text {th }}$ January 2018, Peer review completed $-15^{\text {th }}$ January 2018)

(Accepted $-18^{\text {th }}$ January 2018)

\section{INTRODUCTION}

Internet addiction as defined by Young [1] is as any online-related, compulsive behavior which interferes with normal living and causes severe stress on family, friends, loved ones, and one's work environment. Internet addiction has been called Internet dependency and Internet compulsivity. By any name, it is a compulsive behaviour that completely dominates the addict's life. Internet addicts make the Internet a priority more important than family, friends, and work. The Internet becomes the organizing principle of addicts' lives.

Rosenberg defines self-esteem as "totality of the individual's thoughts and feelings with reference to himself as an object" [2]. Besides self-esteem, self-efficacy or mastery, and self-identities are important parts of the self-concept. Locus of Control measures generalized expectancies for internal versus external control of reinforcement. People with an internal locus of control believe that their own actions determine the rewards that they obtain, while those with an external locus of control believe that their own behaviour doesn't matter much and that rewards in life are generally outside of their control. 
Bahrainian and others investigated the relationship of self-esteem and depression with Internet addiction in university 408 students (150 female and 258 male). A significant correlation emerged between depression, self-esteem and internet addiction. Regression analysis indicated that depression and self-esteem were able to predict the variance of Internet addiction to some extent [3].

A study by Betül and San aimed to examine the role of self-esteem on adolescents' Internet addiction. The sample of the study consisted of 324 adolescents from Trabzon, Turkey [4]. The findings showed that general self-esteem, social self-esteem, family-home self-esteem and total self-esteem were significantly and negatively correlated with Internet addiction.

Ahmet and Murat studied the relationship of internet addiction, social self-efficacy, and academic locus of control. Participants were 311 university students who completed a questionnaire package that included the Online Cognition Scale, the Academic Locus of Control Scale, and the Perceived Social Self-efficacy Scale. Results indicated internal academic locus of control was predicted positively by social self-efficacy. Also, internet addiction was explained negatively by social self-efficacy and internal academic locus of control and positively by external academic locus of control. Results were discussed in the light of literature [5-6].

\section{METHODOLOGY}

\section{Sample Description}

Thirty undergraduate students from of RD National College in Mumbai between 18-21 years of age participated in the current study.

\section{Measures}

Young's Internet Addiction Test (IAT) by Young [1], Rosenberg's Self-Esteem Scale [2] and Rotter's Locus of Control were the three measures used in the current study.

Young's Internet Addiction Test (IAT) has 20 items associated with Internet use, including psychological dependence, compulsive use, withdrawal symptoms and related problems of school, sleep, family and time management. For each item, a graded response can be selected $(1=$ "not at all" to $5=$ "always"). The minimum score is 20 , while the maximum is 100 ; the higher the score, the greater the level of Internet addiction.

Rosenberg Self-Esteem Scale is a 10-item scale that measures global self-worth by measuring both positive and negative feelings about the self. The scale is believed to be uni-dimensional. All items are answered using a 4-point Likert scale format ranging from strongly agree to strongly disagree.

Rotter's Locus of Control [7] is a 13-item questionnaire developed by Rotter. Scores range from 0 to 13. A low score indicates an internal control while a high score indicates external control.

\section{Procedure}

Undergraduate students were approached for their participation and were informed about the relevant ethical issues. Following this, respondents were handed over the questionnaires and were asked to rate their responses for all the three scales used in this study. After they returned the questionnaires, they were thanked for their participation in the research project.

\section{Statistical Analysis}

Descriptive statistics for all the scales were calculated. The appropriate statistical analysis was One Way ANOVA for Internet Addiction and Self-Esteem and One WayANOVAfor Internet Addiction and Locus of Control. The statistical analysis was done through $\mathrm{R}$ Studio is a free and open-source integrated development environment for $\mathrm{R}$, a programming language for statistical computing and graphics. 


\section{RESULTS AND DISCUSSION}

Figure $1 \mathrm{QQ}$ norm for the data

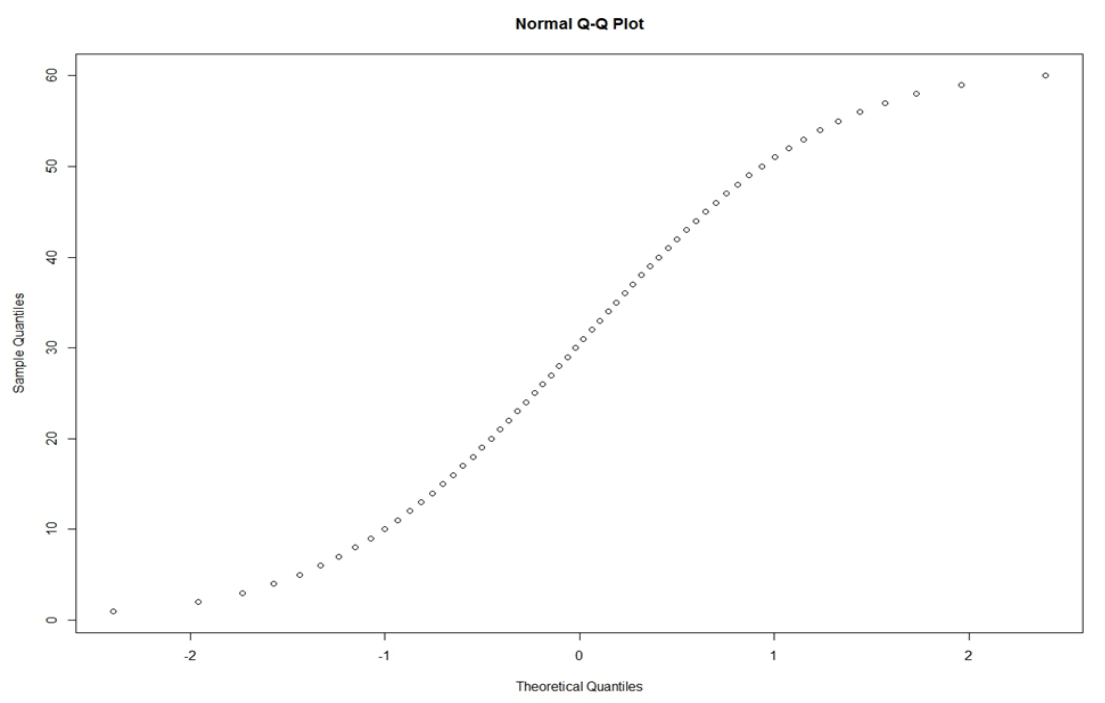

Table 1 One wayANOVA for Internet Addiction and Self-Esteem

\begin{tabular}{|l|l|l|l|l|l|}
\hline & Df & $\begin{array}{l}\text { Sum of } \\
\text { Squares }\end{array}$ & $\begin{array}{l}\text { Mean } \\
\text { Squares }\end{array}$ & F value & \\
\hline & 1 & 238 & 238.5 & 1.745 & NS \\
\hline Residuals & 56 & 7652 & 136.6 & & \\
\hline
\end{tabular}

Table 2 One wayANOVA for Internet Addiction and Locus of control

\begin{tabular}{|l|l|l|l|l|l|}
\hline & Df & $\begin{array}{l}\text { Sum of } \\
\text { Squares }\end{array}$ & $\begin{array}{l}\text { Mean } \\
\text { Squares }\end{array}$ & F value & p value \\
\hline & 1 & 958 & 957.7 & 7.264 & $0.009^{*}$ \\
\hline Residuals & 56 & 7652 & 136.6 & & \\
\hline
\end{tabular}

The results obtained are of the 30 students of R. D. National College who participated in the study. To check the normality of the data qq norm was plotted as seen in the Figure 1 indicating a normal distribution. The above table describes the $\mathrm{F}$ values of the data. Table 1 is One wayANOVA for Internet Addiction and Self-Esteem which as it can be seen from the table is F-value of 1.745 (not significant). The obtained data had high self-esteem thus showing a negative relationship between Internet Addiction and Self-Esteem.

Table 2 is One wayANOVA for Internet Addiction and Locus of control with an F-value of 7.264 significant at '**' 0.01 . Thus, the obtained results are in line with the hypothesis which states to study the relationship between Internet Addiction with Self-Esteem and Locus of Control.

The relationship as found in previous research is perfectly negative for self-esteem and internet addiction and also higher scores on internet addiction is linked with external locus of control.

The results are in line with the previous research by Desara Agaj who studied the impact of the components of the locus of control in internet addiction on 1156 adolescents, aged 15-18, in the city of Tirana [8]. Results showed that a large number of adolescents in Albania have a high risk to develop internet addiction in the nearest future and adolescents with internal locus of control have $35 \%$ less probability to develop internet addition than those with external locus of control (powerful others, 
chance). The study relied on a small sample size of undergraduate students, which prevents generalizability of the findings to the larger student community. Furthermore, using self-report scales could have led to a "social desirability bias", preventing the respondents from revealing their true opinions and feelings. Future research can delve into gender differences with respect to perceived control and psychological wellbeing [9-10].

\section{CONCLUSION}

The present study was validated by the previous researches which have stated that high scores on Internet addiction are negatively related to high self-esteem. Also, as it was found locus of control serves is related to internet addiction that is external locus of control is negatively related to internet addiction.

\section{REFERENCES}

1. Young KS. Internet addiction: The emergence of a new clinical disorder. Cyberpsychol Behav 1998;1(3):237-44.

2. Rosenberg M. Society and the adolescent self-image. Princeton university press; 2015.

3. Bugay AS. Investigation of social-cognitive, emotional and behavioral variables as predictors of self-forgiveness. Unpublished Doctoral Dissertation, Middle East Technical University; 2010.

4. Aydm B, San SV. Internet addiction among adolescents: the role of self-esteem. Proc Soc Behav Sciences. 2011;15:3500-5.

5. İskender M, Akin A. Social self-efficacy, academic locus of control, and internet addiction. Comp Educ 2010;54(4):1101-6.

6. Almajali HK. The influence of family upbringing style and locus of control on the creative thinking of preparatory school learners in the united arab emirates (Doctoral dissertation). Middle East University ; 2016.

7. Rotter JB. Generalized expectancies for internal versus external control of reinforcement. Psychol Monogr Gen Appl 1966;80(1):1-33.

8. Agaj D. The Impact of the Components of the Locus of Control in Internet Addiction, Case of Albania. American Scientific Research Journal for Engineering, Technology, and Sciences (ASRJETS) 2016;18(1):40-4.

9. Fisher RJ. Social desirability bias and the validity of indirect questioning. J Consumer Res 1993;20(2):303-15.

10. Team RC. R: A language and environment for statistical computing. Vienna, Austria: R Foundation for Statistical Computing; 2014.

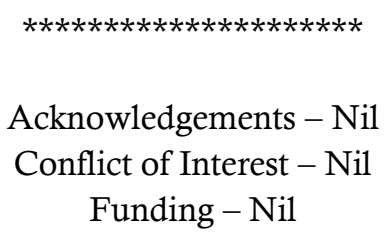

